\title{
Body weight changes in patients with type 2 diabetes and a recent acute coronary syndrome: an analysis from the EXAMINE trial
}

\author{
João Pedro Ferreira ${ }^{1,2^{*}} \mathbb{D}$, Patrick Rossignol ${ }^{1}$, George Bakris ${ }^{3}$, Cyrus Mehta $^{4}$, William B. White ${ }^{5}$ and Faiez Zannad ${ }^{1}$
}

\begin{abstract}
Background: Patients with type 2 diabetes (T2D) may experience frequent body weight changes over time. The prognostic impact of these weight changes (gains or losses) requires further study.

Aims: To study the associations between changes in body weight (intentional or unintentional) with subsequent outcomes.

Methods: The EXAMINE trial included 5380 patients with T2D and a recent acute coronary syndrome, who were randomized to alogliptin or placebo. Time-updated Cox models and mixed effects models were used to test the associations between changes in body weight and subsequent outcomes over a median follow-up of 1.6 (1.0-2.1) years.

Results: During the post-randomization follow-up period, 1044 patients (19.4\%) experienced a weight loss $\geq 5 \%$ of baseline weight, 2677 (49.8\%) had a stable weight, and 1659 (30.8\%) had a $\geq 5 \%$ weight gain. Patients with weight loss were more frequently women and had more co-morbid conditions. In contrast, patients who gained $\geq 5 \%$ weight were more frequently men with less co-morbid conditions. A weight loss $\geq 5 \%$ was independently associated with a higher risk of subsequent adverse outcomes, including all-cause mortality: adjusted HR $(95 \% \mathrm{Cl})=1.79(1.33-2.42)$, $P<0.001$. Similar associations were found for cardiovascular mortality, the composite of cardiovascular mortality or heart failure hospitalization, and the primary outcome. A weight gain $\geq 5 \%$ was independently associated with an increase in the risk of subsequent cardiovascular mortality or heart failure hospitalization only: adjusted HR (95\% $\mathrm{Cl})=1.34(1.02-1.76), \mathrm{P}=0.033$
\end{abstract}

Conclusions: In patients with $\mathrm{T} 2 \mathrm{D}$ who had a recent $\mathrm{ACS} / \mathrm{Ml}, \mathrm{a} \geq 5 \%$ loss of body weight was associated with a higher risk of subsequent cardiovascular events and mortality.

Keywords: Type 2 diabetes, Weight changes, Cardiovascular outcomes

*Correspondence: j.ferreira@chru-nancy.fr; jp7ferreira@hotmail.com ${ }^{1}$ Centre DInvestigation Clinique-Plurithématique Inserm CIC-P 1433, Inserm U1116, CHRU Nancy hopitaux de Brabois, F-CRIN INI-CRCT (Cardiovascular and Renal Clinical Trialists), Université de Lorraine, Institut Lorrain du Coeur et des Vaisseaux Louis Mathieu, 4 Rue du Morvan, 54500 Vandoeuvre lès Nancy, France

Full list of author information is available at the end of the article

\section{Introduction}

Low body weight or low body mass index (BMI) has been associated with poor outcomes in patients with type 2 diabetes [1, 2]. Although, excess weight and obesity increase the risk of T2D and cardiovascular diseases [35], among patients who have developed T2D and other chronic conditions, obesity is not associated with poor outcomes $[2,6]$. This phenomenon has been referred to as the "obesity paradox" and may indicate that patients with lower versus higher body weight may experience 
more cachexia, wasting and frailty [7]. Furthermore, patients with T2D may experience "dynamic" weight changes over the course of the disease, which may have prognostic impact (particularly weight loss), independently of the BMI [2].

An important distinction is whether the weight loss was intentional or unintentional. Observational studies distinguishing intentional from unintentional weight loss suggest that weight loss may be a mortality risk factor regardless of intent to lose weight [8]. Large-scale trials in which an intentional weight loss program was part of the intervention improved diabetes control and cardiovascular risk factors but had a neutral effect on morbidity and mortality outcomes [9].

Using data from the Cardiovascular Outcomes Study of Alogliptin in Patients With Type 2 Diabetes and Acute Coronary Syndrome (EXAMINE) trial, that included patients with T2D who had a recent acute coronary syndrome (ACS) or myocardial infarction (MI) randomly assigned to either alogliptin or placebo [10], we explored the factors associated with changes in body weight (loss and/or gain), the effect of alogliptin on body weight over time, and he prognostic associations of weight changes.

\section{Methods}

\section{Study design}

Details of the EXAMINE trial design have been previously published [10, 11]. In short, a total of 5380 patients with T2D who had a recent ACS were randomly assigned to either alogliptin or placebo.

In the overall population, alogliptin significantly reduced glycated hemoglobin (HBA1c) without altering the rates of major adverse cardiovascular events over a median (percentile ${ }_{25-75}$ ) follow-up of 1.6 (percentile ${ }_{25-75}: 1.0-2.1$ ) years.

The steering committee, consisting of academic members and three nonvoting representatives of the sponsor (Takeda Development Center Americas), designed and oversaw the conduct of the trial. An independent data and safety monitoring committee monitored the trial and had access to the unblinded data.

\section{Study patients}

Patients were eligible for enrolment if they had received a diagnosis of T2D, were receiving antidiabetic therapy (other than a DPP-4 inhibitor or GLP-1 analogue) and had an ACS (MI and unstable angina requiring hospitalization) within 15 to 90 days prior to randomization. Major exclusion criteria were a diagnosis of type 1 diabetes, unstable cardiac disorders (e.g., advanced heart failure, refractory angina, uncontrolled arrhythmias, critical valvular heart disease, or severe uncontrolled hypertension), active cancers, and dialysis within 14 days before screening.

Institutional Review Board approval was obtained, ethics approval was obtained at each participating site, and all patients provided informed consent to participate in the trial. The EXAMINE trial is registered with the clinicaltrials.gov number NCT00968708.

\section{Body weight changes}

Body weight changes were calculated at each post-randomization study visit (1 month, 3 months, 6 months, 9 months, 12 months, and every 4 months thereafter) as the percentage (\%) of weight change from randomization to study visit. Patients were further categorized by weight losses and gains during the follow-up ( $\geq 5 \%$ and $\geq 10 \%$ ).

\section{Study outcomes}

The primary endpoint in EXAMINE was a composite of death from cardiovascular causes, nonfatal MI, or nonfatal stroke, adjudicated by an independent committee blinded to treatment assignment. In the present analysis we also studied the association of weight changes with subsequent occurrence of cardiovascular death or HF hospitalization, cardiovascular death, and all-cause death.

\section{Statistical analysis}

For descriptive statistics, EXAMINE patients were divided in those experiencing any weight loss or gain $\geq 5 \%$ and $\geq 10 \%$ vs. those not experiencing such weight changes. Patients' characteristics are presented as mean \pm standard deviation, median (percentile ${ }_{25-75}$ ), or numbers and percentages, as appropriate. The groups were compared using parametric or non-parametric tests for continuous variables and chi-square tests for categorical variables. To study the effect of alogliptin (vs. placebo) on weight over time, mixed effects linear regression models were used with continuous weight as outcome variable, and study visit, treatment (alogliptin or placebo), study visit by treatment interaction, diabetes duration, insulin, metformin, statins, current smoking, heart failure history, anemia, hypertension, body mass index (BMI), estimated glomerular filtration rate (eGFR), and diuretics as dependent variables, with random effects at the patient level, and unstructured covariance matrix to allow for correlation between measures. Mixed effects logistic regression models were performed to study the effect of alogliptin on weight loss or gain $(\geq 5 \%$ and $\geq 10 \%$ ) throughout the follow-up.

The impact of weight changes ( $\geq 5 \%$ and $\geq 10 \%$ loss or gain) on outcomes was studied with time-updated Cox models (that take into account the most recent value before an event), adjusting for treatment (alogliptin or 
placebo), diabetes duration, insulin, metformin, statins, current smoking, heart failure history, anemia, hypertension, BMI, eGFR, and diuretics. An interaction between weight changes and BMI was tested for each outcome, to assess whether the impact of weight changes on outcomes could vary by baseline BMI i.e., if it would be different in obese $\left(\mathrm{BMI} \geq 30 \mathrm{Kg} / \mathrm{m}^{2}\right)$ vs. non-obese $(\mathrm{BMI}<30$ $\mathrm{Kg} / \mathrm{m}^{2}$ ) patients. The association between time-update BMI and subsequent outcomes was studied across quintiles of BMI $\left(\leq 22,23-25,26-30,31-35,>35 \mathrm{Kg} / \mathrm{m}^{2}\right)$ adjusting for the same variables above described (except BMI which is the variable of interest) and using the middle category $\left(26-30 \mathrm{Kg} / \mathrm{m}^{2}\right)$ as the referent category. The adjustment variables were selected for their prognostic importance, based on previous EXAMINE publications and differences found in Table $1[12,13,14]$. The last available value was carried forward whenever missing values occurred in the time-updated models. Two-tailed P values $<0.05$ were considered statistically significant. Statistical analyses were performed using STATA ${ }^{\circledR}$ Statistical Software version 17.0 (STATA Corp, College Station, Texas).

\section{Results}

Baseline characteristics of the patients by weight changes Of the 5380 randomized patients, 1044 (19.4\%) experienced a weight loss $\geq 5 \%$ of baseline weight, 2677 (49.8\%) had a stable weight within the 5\% range, and 1659 (30.8\%) gained weight $\geq 5 \%$ of their baseline weight. The histogram representing the weight changes throughout the follow-up is displayed in Additional file 1: Fig. S1. Compared to patients with a stable weight, those who lost $\geq 5 \%$ of their weight were more frequently women (38.0 vs. $31.5 \%$ ), had higher body weight and BMI at baseline ( 84.5 vs. $83.6 \mathrm{Kg}$ and 30.5 vs. $29.7 \mathrm{Kg} / \mathrm{m}^{2}$, respectively), had a more frequent history of peripheral artery disease (11.7 vs. 9.9\%), atrial fibrillation (9.1 vs. $7.1 \%$ ), anemia (30.0 vs. $23.3 \%$ ), and kidney disease (eGFR $<60$ $\mathrm{ml} / \mathrm{min}$ : 33.8 vs. $28.4 \%$ ), with a more frequent use of diuretics ( 41.4 vs. $36.9 \%$ ) (Table 1 ). In contrast, patients who gained $\geq 5 \%$ weight were younger, more frequently men with lower weight and BMI at baseline, and less comorbid conditions including HF, peripheral artery disease, atrial fibrillation, anemia, and kidney disease (Table 1). Similar characteristics were observed for patients who had weight changes more than $10 \%$ of their baseline weight (Additional file 1: Table S1).

\section{Effect of alogliptin on body weight}

Patients randomized to alogliptin (vs. placebo) had a small increase in mean body weight throughout the follow-up of +0.54 (95\% CI 0.08 to 0.99$) \mathrm{Kg}, \mathrm{P}=0.020$
(Fig. 1), but did not lead to increases in body weight of $\geq 5 \%$ or $\geq 10 \%$ (Additional file 1: Table S2).

\section{Body weight changes and subsequent outcomes}

Weight losses of $\geq 5 \%$ and $\geq 10 \%$ were independently associated with a higher risk of cardiovascular and allcause mortality: weight loss $\geq 5 \%$ all-cause mortality adjusted HR $(95 \% \mathrm{CI})=1.79(1.33-2.42), \mathrm{P}<0.001$ and weight loss $\geq 10 \%$ all-cause mortality adjusted HR $(95 \%$ $\mathrm{CI}$ ) 2.07 (1.31-3.25), $\mathrm{P}=0.002$ (Table 2 and Fig. 2) . Similar associations were found for cardiovascular mortality, the composite of cardiovascular mortality or HF hospitalization, and the primary MACE outcome. A weight gain $\geq 5 \%$ was only independently associated with a small increase in the risk of subsequent cardiovascular mortality or HF hospitalization: adjusted HR (95\% $\mathrm{CI})=1.34 \quad(1.02-1.76), \mathrm{P}=0.033$. A weight gain $\geq 10 \%$ was not associated with risk subsequent events. Baseline BMI did not influence the prognostic impact of weight changes (interaction $\mathrm{P}>0.1$ for all outcomes) (Table 2).

\section{Body mass index and subsequent outcomes}

Compared to patients with a BMI between 26 and $30 \mathrm{~kg} /$ $\mathrm{m}^{2}$, those with a BMI $\leq 22 \mathrm{~kg} / \mathrm{m}^{2}$ had a higher risk of cardiovascular outcomes including all-cause and cardiovascular mortality: adjusted HR $(95 \% \mathrm{CI})=2.07(1.29-3.30)$, $\mathrm{P}=0.002$ and $=1.78(1.01-3.16), \mathrm{P}=0.047$, respectively. Patients with a BMI $>30 \mathrm{~kg} / \mathrm{m}^{2}$ (including those with a $\mathrm{BMI}>35 \mathrm{~kg} / \mathrm{m}^{2}$ ) had a lower risk of a primary outcome event: adjusted HR (95\% CI) $=0.75(0.60-0.96)$, $\mathrm{P}=0.020$ for patients with a BMI between 31 and $35 \mathrm{~kg} /$ $\mathrm{m}^{2}$ and $=0.61(0.41-0.92), \mathrm{P}=0.017$ for patients with a BMI $>35 \mathrm{~kg} / \mathrm{m}^{2}$ (Additional file 1:Table S3).

\section{Discussion}

The present study shows that patients who experienced a weight loss of $5 \%$ or greater had more co-morbid conditions (e.g., peripheral artery disease, atrial fibrillation, anemia, and chronic kidney disease) than those who did not lose or even gained weight. A weight loss of 5\% or more of body weight was independently associated with a higher risk of cardiovascular events and mortality. Weight gain was only modestly associated with an increased risk of the cardiovascular composite that included mortality plus HF hospitalizations. This study also showed that a low BMI $\left(\leq 22 \mathrm{~kg} / \mathrm{m}^{2}\right)$ was associated with a higher risk of subsequent events, whereas a high BMI (even $>35 \mathrm{~kg} / \mathrm{m}^{2}$ ) was associated with a lower risk of primary outcome events. Alogliptin (vs. placebo) led to a slight $(0.5 \mathrm{~kg}$ on average) increase in body weight throughout the follow-up and did not increase the odds of experiencing weight gains in excess of $5 \%$ of baseline weight. 
Table. 1 Baseline characteristics of the patients by $5 \%$ weight change from baseline

\begin{tabular}{|c|c|c|c|c|}
\hline Characteristic & Weight loss $\geq \mathbf{5} \%$ & Stable weight & Weight gain $\geq 5 \%$ & P-value \\
\hline N & 1044 & 2677 & 1659 & \\
\hline Age, years & $61.3 \pm 10.0$ & $61.7 \pm 10.0$ & $59.3 \pm 9.6$ & $<0.001$ \\
\hline Age $>65$ year & $391(37.5 \%)$ & $1052(39.3 \%)$ & $464(28.0 \%)$ & $<0.001$ \\
\hline Female, n (\%) & 397 (38.0\%) & $843(31.5 \%)$ & 489 (29.5\%) & $<0.001$ \\
\hline Diabetes duration, years & $7.5(2.8,14.0)$ & $7.1(2.9,13.3)$ & $6.9(2.4,14.0)$ & 0.43 \\
\hline Glycated hemoglobin, \% & $8.0 \pm 1.1$ & $8.0 \pm 1.1$ & $8.1 \pm 1.1$ & 0.030 \\
\hline Insulin, n (\%) & 300 (28.7\%) & $782(29.2 \%)$ & $523(31.5 \%)$ & 0.19 \\
\hline Metformin, n (\%) & 701 (67.1\%) & $1776(66.3 \%)$ & $1085(65.4 \%)$ & 0.63 \\
\hline Sulfonylureas, n (\%) & $445(42.6 \%)$ & $1270(47.4 \%)$ & $788(47.5 \%)$ & 0.019 \\
\hline Thiazolidinediones, n (\%) & $38(3.6 \%)$ & $49(1.8 \%)$ & $44(2.7 \%)$ & 0.004 \\
\hline Weight at baseline, Kg & $84.5 \pm 21.0$ & $83.6 \pm 18.6$ & $78.5 \pm 18.3$ & $<0.001$ \\
\hline $\mathrm{BMI}$ at baseline, $\mathrm{Kg} / \mathrm{m}^{2}$ & $30.5 \pm 6.3$ & $29.7 \pm 5.4$ & $28.4 \pm 5.3$ & $<0.001$ \\
\hline Race & & & & $<0.001$ \\
\hline White & 735 (70.4\%) & $2051(76.6 \%)$ & $1123(67.7 \%)$ & \\
\hline Asian & $232(22.2 \%)$ & 479 (17.9\%) & $378(22.8 \%)$ & \\
\hline Black & $57(5.5 \%)$ & $79(3.0 \%)$ & $80(4.8 \%)$ & \\
\hline Other & $20(1.9 \%)$ & $68(2.5 \%)$ & $78(4.7 \%)$ & \\
\hline Current smoker, n (\%) & 145 (13.9\%) & $374(14.0 \%)$ & $215(13.0 \%)$ & 0.62 \\
\hline Hypertension, n (\%) & 889 (85.2\%) & $2279(85.1 \%)$ & $1301(78.4 \%)$ & $<0.001$ \\
\hline HF history, n (\%) & $298(28.5 \%)$ & $836(31.2 \%)$ & $399(24.1 \%)$ & $<0.001$ \\
\hline Prior stroke, n (\%) & $85(8.1 \%)$ & $190(7.1 \%)$ & $113(6.8 \%)$ & 0.40 \\
\hline PAD, n (\%) & $122(11.7 \%)$ & $266(9.9 \%)$ & $126(7.6 \%)$ & 0.001 \\
\hline Atrial fibrillation, n (\%) & $95(9.1 \%)$ & $190(7.1 \%)$ & $91(5.5 \%)$ & 0.002 \\
\hline MI (index event), $\mathrm{n}(\%)$ & 794 (76.3\%) & $1993(74.7 \%)$ & $1365(82.3 \%)$ & $<0.001$ \\
\hline Unstable angina (index event), n (\%) & $246(23.7 \%)$ & $675(25.3 \%)$ & $293(17.7 \%)$ & \\
\hline Hemoglobin, g/dl & $13.2 \pm 1.6$ & $13.6 \pm 1.6$ & $13.4 \pm 1.5$ & $<0.001$ \\
\hline Anemia, n (\%) & $312(30.0 \%)$ & $623(23.3 \%)$ & $433(26.1 \%)$ & $<0.001$ \\
\hline $\mathrm{eGFR}, \mathrm{ml} / \mathrm{min} / 1.73 \mathrm{~m}^{2}$ & $67.5 \pm 21.2$ & $71.1 \pm 21.1$ & $72.8 \pm 21.8$ & $<0.001$ \\
\hline $\mathrm{eGFR}<60 \mathrm{ml} / \mathrm{min}, \mathrm{n}(\%)$ & $353(33.8 \%)$ & $761(28.4 \%)$ & $451(27.2 \%)$ & $<0.001$ \\
\hline Heart rate, bpm & $72.1 \pm 11.2$ & $70.8 \pm 10.7$ & $71.8 \pm 10.7$ & $<0.001$ \\
\hline $\mathrm{SBP}, \mathrm{mmHg}$ & $129.7 \pm 17.4$ & $129.9 \pm 15.8$ & $127.1 \pm 17.3$ & $<0.001$ \\
\hline $\mathrm{SBP}>140 / 90 \mathrm{mmHg}, \mathrm{n}(\%)$ & $238(22.8 \%)$ & $545(20.4 \%)$ & $297(17.9 \%)$ & 0.007 \\
\hline Total cholesterol, mg/dl & $146(123,148)$ & $149(126,178)$ & $143(122,173)$ & 0.001 \\
\hline HDL cholesterol, mg/dl & $42(36,48)$ & $42(36,49)$ & $42(35,48)$ & 0.11 \\
\hline LDL cholesterol, mg/dl & $72(55,97)$ & $74(55,97)$ & $70(53,94)$ & 0.010 \\
\hline Triglycerides, mg/dl & $138(102,192)$ & $143(104,200)$ & $139(102,191)$ & 0.12 \\
\hline Antiplatelets at baseline, n (\%) & $1008(96.6 \%)$ & $2600(97.1 \%)$ & 1624 (97.9\%) & 0.10 \\
\hline Beta-blockers at baseline, n (\%) & $836(80.1 \%)$ & $2220(82.9 \%)$ & $1355(81.7 \%)$ & 0.12 \\
\hline Statins at baseline, n (\%) & $930(89.1 \%)$ & $2402(89.7 \%)$ & $1534(92.5 \%)$ & 0.003 \\
\hline CCBs at baseline, $\mathrm{n}(\%)$ & $244(23.4 \%)$ & $641(23.9 \%)$ & $312(18.8 \%)$ & $<0.001$ \\
\hline Diuretics at baseline, n (\%) & $432(41.4 \%)$ & $988(36.9 \%)$ & $594(35.8 \%)$ & 0.010 \\
\hline ACEi or ARB at baseline, $\mathrm{n}(\%)$ & $856(82.0 \%)$ & $2227(83.2 \%)$ & $1328(80.0 \%)$ & 0.033 \\
\hline Randomization to alogliptin & $541(51.8 \%)$ & $1332(49.8 \%)$ & $828(49.9 \%)$ & 0.51 \\
\hline
\end{tabular}

BMI, body mass index; PAD, peripheral artery disease; MI, myocardial infarction; eGFR, estimated glomerular filtration rate; SBP, systolic blood pressure; CCBs, calcium channel blockers; $\mathrm{ACEi} / \mathrm{ARBs}$, angiotensin converting enzyme inhibitors/angiotensin receptor blockers

Weight loss has been associated with an increased mortality risk in patients with T2D. Data from the ORIGIN trial, including patients with established cardiovascular risk factors and T2D or pre-diabetes, also showed that weight loss was associated with increases in the risk of cardiovascular events and mortality, whereas weight gain 


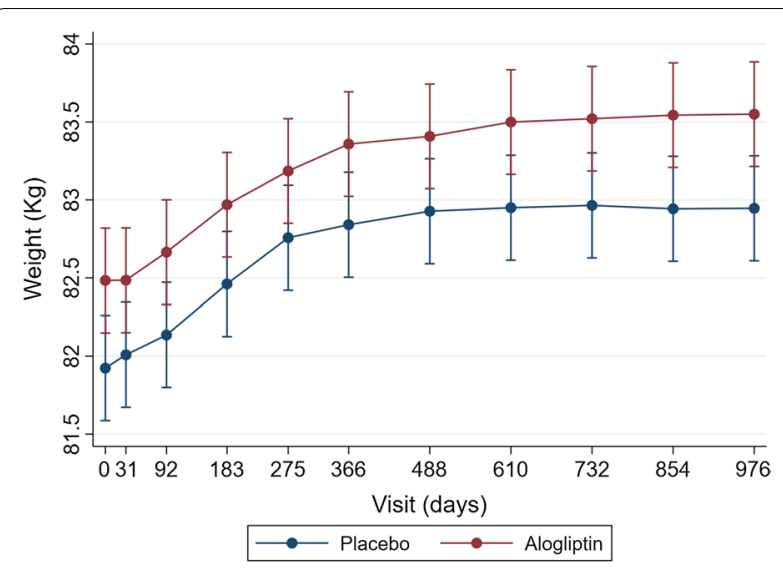

Fig. 1 Effect of alogliptin (vs. placebo) on body weight throughout the follow-up

was not associated with adverse outcomes [2]. Moreover, the ORIGIN trial also showed that patients with a $\mathrm{BMI}<22 \mathrm{~kg} / \mathrm{m}^{2} \mathrm{had}$ an increased risk of adverse outcomes and that overweight or obese patients had a lower risk of cardiovascular events [2]. Long-term follow-up data from 444 patients in the Diabetes Care in General Practice study, suggested that weight loss was associated with an increased risk of mortality, regardless of the intention to lose or not to lose weight [8]. Similar associations were found in patients with a recent MI complicated with HF [6], and in patients with HF and a reduced ejection fraction regardless of the T2D status $[15,16]$. Our study confirms these findings in a unique high cardiovascular risk T2D population with recent acute coronary syndromes and regardless of the baseline BMI (i.e., a weight loss $\geq 5 \%$ may be associated with a poor prognosis even in obese patients at baseline (with a BMI $>30 \mathrm{~kg} / \mathrm{m}^{2}$ ). However, data from large randomized controlled trials do not confirm these observational findings (see below), suggesting that in observational studies it may be difficult to distinguish intentional from unintentional weight loss and control for confounding i.e., the findings from observational studies likely represent a "reverse causation" or "reverse epidemiology" phenomenon [17, 18]. The LOOK-AHEAD trial randomized 5145 overweight or obese T2D patients to an intensive lifestyle intervention that promoted weight loss (through decreased caloric intake and increased physical activity) (intervention group) or to receive diabetes support and education (control group). Patients in the intervention group lost $8.6 \%$ of their body weight in the first year vs. $0.7 \%$ in the control group. Patients in the intervention group also had greater reductions in glycated hemoglobin, and improvements in fitness and cardiovascular risk factors, without increase on morbidity and mortality [9]. Despite lower risk population in the LOOK-AHEAD trial compared with EXAMINE, these findings suggest that intentional weight loss does not increase the mortality risk; findings also supported by smaller "mechanistic" studies where weight loss was intentional, either induced by exercise training or by drugs that also improve cardiovascular outcomes, such as SGLT2 inhibitors [19, 20].

Although in EXAMINE we could not ascertain whether weight loss was intentional or unintentional, it is possible that the weight loss that drove the association with an increased risk of events represent unintentional weight losses since patients experiencing weight losses $\geq 5 \%$ had higher rates of comorbid conditions at baseline-including peripheral artery disease, atrial fibrillation, anemia, and chronic kidney disease-all of which are associated with poor outcomes either individually or in combination and across multiple populations including those with diabetes [21-24]. Together, these findings suggest that clinicians should be wary of unintentional weight loss in patients with T2D, particularly if the weight loss is in excess of $5 \%$ of body weight, where weight loss should be thoroughly investigated.

In contrast to weight loss which was strongly and independently associated with a higher risk of all cardiovascular outcomes and mortality, weight gain $\geq 5 \%$ (but not $\geq 10 \%$ ) was associated only with a higher risk of HF hospitalizations, suggesting that some of the increase in body weight may reflect congestion and fluid accumulation leading to HF [25]. Other observational studies in patients with T2D found that a weight gain was associated with a lower risk of cardiovascular outcomes [26].

\section{Limitations}

There are certain limitations to our analysis. We could not distinguish intentional from unintentional weight loss, because this information was not recorded prospectively; however, as pointed out in "Discussion" section, we believe that most of the weight loss cases were probably unintentional and potentially linked to cachexia in a population with a high burden of comorbid conditions. The findings in the study are observational and prone to confounding; therefore, causality cannot be established. Some cancer diagnoses might have passed unnoticed, and it is difficult to ascertain their contribution to the mortality seen in our study. The EXAMINE trial was published in 2013, a time where therapies that improve cardiovascular outcomes of patients with type 2 diabetes (e.g., SGLT2 inhibitors and GLP1 receptor agonists) where not available yet; therefore, our findings may not be applicable to more contemporary cohorts. Echocardiography was not performed in EXAMINE, which could have provided more insight on the underlying causes of weight gain 
Table.2 Association of weight change with subsequent outcomes

\begin{tabular}{|c|c|c|c|}
\hline Outcome/weight changes & Crude HR $(95 \% \mathrm{Cl})$ & Adj. HR $(95 \% \mathrm{Cl}) *$ & P-value \\
\hline \multicolumn{4}{|l|}{ All-cause death } \\
\hline Weight loss $\geq 5 \%$ & $2.15(1.61-2.87)$ & $1.79(1.33-2.42)$ & $<0.001$ \\
\hline Stable weight & Ref. & Ref. & - \\
\hline Weight gain $\geq 5 \%$ & $0.99(0.73-1.32)$ & $1.01(0.74-1.36)$ & 0.96 \\
\hline Weight loss $\geq 10 \%$ & $2.74(1.78-4.25)$ & $2.07(1.31-3.25)$ & 0.002 \\
\hline Stable weight & Ref. & Ref. & - \\
\hline Weight gain $\geq 10 \%$ & $0.90(0.54-1.52)$ & $0.83(0.50-1.41)$ & 0.50 \\
\hline \multicolumn{4}{|l|}{ Cardiovascular death } \\
\hline Weight loss $\geq 5 \%$ & $2.21(1.57-3.10)$ & $1.84(1.30-2.61)$ & 0.001 \\
\hline Stable weight & Ref. & Ref. & - \\
\hline Weight gain $\geq 5 \%$ & $1.16(0.83-1.62)$ & $1.21(0.86-1.70)$ & 0.28 \\
\hline Weight loss $\geq 10 \%$ & $2.56(1.50-4.37)$ & $1.89(1.10-3.26)$ & 0.021 \\
\hline Stable weight & Ref. & Ref. & - \\
\hline Weight gain $\geq 10 \%$ & $0.94(0.51-1.73)$ & $0.88(0.48-1.63)$ & 0.68 \\
\hline \multicolumn{4}{|l|}{ CVD/HFH } \\
\hline Weight loss $\geq 5 \%$ & $2.61(1.99-3.41)$ & $2.19(1.66-2.89)$ & $<0.001$ \\
\hline Stable weight & Ref. & Ref. & - \\
\hline Weight gain $\geq 5 \%$ & $1.29(0.99-1.69)$ & $1.34(1.02-1.76)$ & 0.033 \\
\hline Weight loss $\geq 10 \%$ & $3.59(2.42-5.33)$ & $2.83(1.87-4.23)$ & $<0.001$ \\
\hline Stable weight & Ref. & Ref. & - \\
\hline Weight gain $\geq 10 \%$ & $1.07(0.67-1.72)$ & $1.00(0.63-1.61)$ & 0.99 \\
\hline \multicolumn{4}{|l|}{ Primary outcome } \\
\hline Weight loss $\geq 5 \%$ & $1.87(1.49-2.36)$ & $1.67(1.32-2.10)$ & $<0.001$ \\
\hline Stable weight & Ref. & Ref. & - \\
\hline Weight gain $\geq 5 \%$ & $0.91(0.73-1.15)$ & $0.94(0.74-1.18)$ & 0.57 \\
\hline Weight loss $\geq 10 \%$ & $2.53(1.76-3.63)$ & $2.14(1.49-3.08)$ & $<0.001$ \\
\hline Stable weight & Ref. & Ref. & - \\
\hline Weight gain $\geq 10 \%$ & $0.84(0.56-1.27)$ & $0.82(0.54-1.24)$ & 0.34 \\
\hline
\end{tabular}

$\mathrm{CVD} / \mathrm{HFH}$, composite of cardiovascular death or heart failure hospitalization; The primary outcome was a composite of myocardial infarction, stroke, or cardiovascular death

*Model adjusted on randomized treatment (alogliptin or placebo), age, sex, diabetes duration, insulin, metformin, statins, current smoking, heart failure history, anemia, hypertension, body mass index, estimated glomerular filtration rate, diuretics

The P-value is for the adjusted model

Baseline body mass index (BMI $\geq 30 \mathrm{vs.}<30 \mathrm{Kg} / \mathrm{m}^{2}$ ) did not modify the associations between weight changes and subsequent outcomes:

$P$ for interaction $5 \%$ weight change $\times$ BMI for all-cause mortality $=0.73$

$P$ for interaction $10 \%$ weight change $\times$ BMI for all-cause mortality $=0.27$

$\mathrm{P}$ for interaction $5 \%$ weight change $\times \mathrm{BMI}$ for cardiovascular mortality $=0.76$

$\mathrm{P}$ for interaction $10 \%$ weight change $\times \mathrm{BMI}$ for cardiovascular mortality $=0.70$

$P$ for interaction $5 \%$ weight change $\times$ BMI for cardiovascular mortality or heart failure hospitalization $=0.51$

$\mathrm{P}$ for interaction $10 \%$ weight change $\times \mathrm{BMI}$ for cardiovascular mortality or heart failure hospitalization $=0.17$

$P$ for interaction $5 \%$ weight change $\times \mathrm{BMI}$ for the primary outcome $=0.58$

$P$ for interaction $10 \%$ weight change $\times \mathrm{BMI}$ for the primary outcome $=0.70$

which could represent worsening heart failure. The median follow-up of EXAMINE was relatively short (1.6 years), a longer follow-up time could have provided more information on the aggravation of chronic conditions, more frequent weight changes, and outcome events.

\section{Conclusions}

In patients with T2D who had a recent acute coronary syndrome, a weight loss of greater than $5 \%$ of body weight was associated with a higher risk of subsequent cardiovascular events and mortality. 


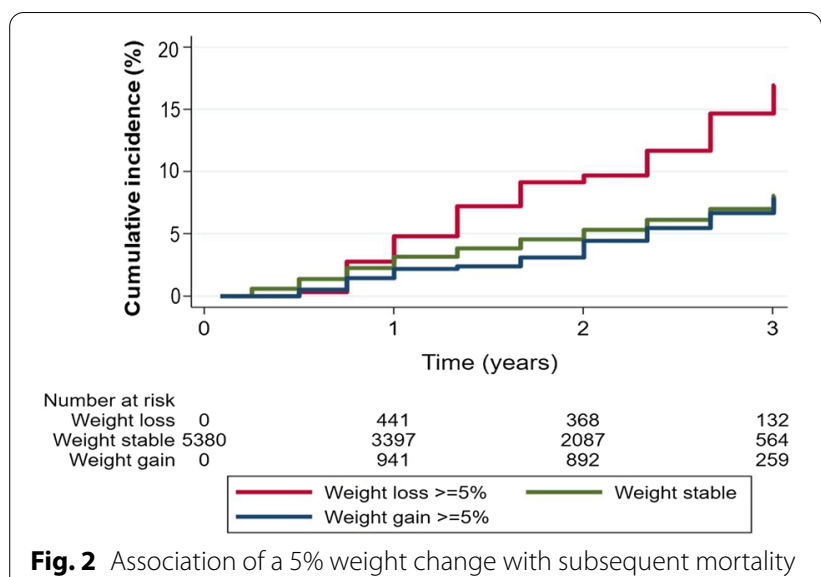

\section{Supplementary Information}

The online version contains supplementary material available at https://doi. org/10.1186/s12933-021-01382-8.

Additional file 1: Table S1. Baselinecharacteristics of the patients by $10 \%$ weight change from baseline. Table S2. Effect of alogliptin onweight change $\geq 5 \%$ and $\geq 10 \%$. Table $\mathbf{S 3}$. Association of body mass index with outcomes. Figure $\mathbf{S} 1$. Histogram representing the weight changes throughout thefollow-up.

\section{Acknowledgements}

EXAMINE is a clinical trial sponsored by Takeda Global Research and Development Center, Inc., Deerfield, IL. The authors are solely responsible for the design of the study, all study analyses, and the drafting and editing of the manuscript and its final contents.

Clinical trials identifier: Clinicaltrials.gov-NCT00968708.

JPF, PR, FZ are supported by a public grant overseen by the French National Research Agency (ANR) as part of the second "Investissements d'Avenir" programme (ANR-15-RHU-0004). All the other authors have nothing to disclose with regards to this manuscript.

Dr. João Pedro Ferreira is the guarantor of this work and, as such, had full access to all the data in the study and takes responsibility for the integrity of the data and the accuracy of the data analysis.

\section{Authors' contributions}

JPF wrote the manuscript, performed the statistical analysis and made critical revisions; CM contributed to the oversight of the EXAMINE trial, as a steering committee member and to discussion and reviewed/edited the manuscript including the revision of the statistical methods and analysis; GB contributed to the oversight of the EXAMINE trial, as a steering committee member and reviewed/edited the manuscript; PR reviewed/edited the manuscript; WBW contributed to the oversight of the EXAMINE trial, as the principal investigator of the trial, and reviewed/edited the manuscript; FZ contributed to the oversight of the EXAMINE trial, as a steering committee member discussion and critically reviewed and edited the manuscript.

\section{Funding}

The EXAMINE study was funded by Takeda but the present analysis did not receive funding.

\section{Availability of data and materials}

The data and materials may be available upon reasonable request.

\section{Declarations}

Ethics approval and consent to participate

Institutional Review Board approval was obtained, ethics approval was obtained at each participating site, and all patients provided informed consent to participate in the trial.

\section{Consent for publication}

Not applicable.

\section{Competing interests}

Dr. Ferreira is a consultant for Boehringer-Ingelheim, and receives research support from AstraZeneca and Novartis. Dr. Rossignol reports personal fees from Ablative Solutions, AstraZeneca, Bayer, Boehringer-Ingelheim, Corvidia, CVRx, Fresenius, G3P (stocks), Grunenthal, Idorsia, KBP, Novartis, NovoNordisk, Relypsa, Sanofi, Sequana Medical, Servier, Stealth Peptides, Vifor, Vifor Fresenius Medical Care Renal Pharma; and Cofounder: CardioRenal, a company developing sensors for the home monitoring of potassium and creatinine. Dr. Zannad reports personal fees from Boehringer Ingelheim during the conduct of the study; personal fees from Janssen, Novartis, Boston Scientific, Amgen, CVRx, AstraZeneca, Vifor Fresenius, Cardior, Cereno pharmacuetical, Applied Therapeutics, Merck, Bayer, and Cellprothera outside the submitted work; and other support from CVCT and Cardiorenal, outside the submitted work. Dr. Bakris, has received personal fees from Takeda Development Center, is a consultant for Merck, Relypsa, and is on the steering committee for international renal/CV outcomes trials for Janssen, Bayer, Vascular Dynamics. Dr. White has received research support from the National Institute of Aging $(\mathrm{NIH})$ and personal fees from Takeda Development Center (Deerfield, IL, USA) during the conduct of the EXAMINE trial until 2016 (Steering Committee Chair). All the other authors reported not having potential conflicts of interest relevant to this article.

\section{Author details}

${ }^{1}$ Centre DInvestigation Clinique-Plurithématique Inserm CIC-P 1433, Inserm U1116, CHRU Nancy hopitaux de Brabois, F-CRIN INI-CRCT (Cardiovascular and Renal Clinical Trialists), Université de Lorraine, Institut Lorrain du Coeur et des Vaisseaux Louis Mathieu, 4 Rue du Morvan, 54500 Vandoeuvre lès Nancy, France. ${ }^{2}$ Cardiovascular Research and Development Center, Faculty of Medicine, University of Porto, Porto, Portugal. ${ }^{3}$ Department of Medicine, American Heart Association Comprehensive Hypertension Center, University of Chicago, Chicago, IL, USA. ${ }^{4}$ Cytel Corporation, Cambridge, MA, USA. ${ }^{5}$ Calhoun Cardiology Center, University of Connecticut School of Medicine, Farmington, CT, USA.

Received: 28 July 2021 Accepted: 7 September 2021 Published online: 14 September 2021

\section{References}

1. Salehidoost R, Mansouri A, Amini M, Yamini SA, Aminorroaya A. Body mass index and the all-cause mortality rate in patients with type 2 diabetes mellitus. Acta Diabetol. 2018;55(6):569-77. https://doi.org/10.1007/ s00592-018-1126-y.

2. Doehner W, Gerstein HC, Ried J, et al. Obesity and weight loss are inversely related to mortality and cardiovascular outcome in prediabetes and type 2 diabetes: data from the ORIGIN trial. Eur Heart J. 2020;21(28):2668-77. https://doi.org/10.1093/eurheartj/ehaa293.

3. Narayan KM, Boyle JP, Thompson TJ, Gregg EW, Williamson DF. Effect of BMI on lifetime risk for diabetes in the U.S. Diabetes Care 2007;30(6):1562-6. https://doi.org/10.2337/dc06-2544.

4. Whitlock G, Lewington S, Sherliker P, et al. Body-mass index and causespecific mortality in 900000 adults: collaborative analyses of 57 prospective studies. Lancet. 2009;28(9669):1083-96. https://doi.org/10.1016/ s0140-6736(09)60318-4. 
5. Berrington de Gonzalez A, Hartge P, Cerhan JR, et al. Body-mass index and mortality among 1.46 million white adults. N Engl J Med. 2010;2(23):2211-9. https://doi.org/10.1056/NEJMoa1000367.

6. Stienen S, Ferreira JP, Girerd N, et al. Mean BMI, visit-to-visit BMI variability and BMI changes during follow-up in patients with acute myocardial infarction with systolic dysfunction and/or heart failure: insights from the High-Risk Myocardial Infarction Initiative. Clin Res Cardiol. 2019;108(11):1215-25. https://doi.org/10.1007/s00392-019-01453-7.

7. Costanzo P, Cleland JG, Pellicori P, et al. The obesity paradox in type 2 diabetes mellitus: relationship of body mass index to prognosis: a cohort study. Ann Intern Med. 2015;5(9):610-8. https://doi.org/10.7326/ m14-1551.

8. Køster-Rasmussen R, Simonsen MK, Siersma V, Henriksen JE, Heitmann BL, de Fine Olivarius N. Intentional weight loss and longevity in overweight patients with type 2 diabetes: a population-based cohort study. PLoS ONE. 2016;11(1):e0146889. https://doi.org/10.1371/journal.pone.0146889.

9. Wing RR, Bolin P, Brancati FL, et al. Cardiovascular effects of intensive lifestyle intervention in type 2 diabetes. N Engl J Med. 2013;11(2):145-54. https://doi.org/10.1056/NEJMoa1212914.

10. White WB, Bakris GL, Bergenstal RM, et al. EXamination of cArdiovascular outcoMes with alogliptIN versus standard of carE in patients with type 2 diabetes mellitus and acute coronary syndrome (EXAMINE): a cardiovascular safety study of the dipeptidyl peptidase 4 inhibitor alogliptin in patients with type 2 diabetes with acute coronary syndrome. Am Heart J. 2011;162(4):620-1. https://doi.org/10.1016/j.ahj.2011.08.004.

11. White WB, Cannon CP, Heller SR, et al. Alogliptin after acute coronary syndrome in patients with type 2 diabetes. N Engl J Med. 2013;3(14):132735. https://doi.org/10.1056/NEJMoa1305889.

12. Ferreira JP, Sharma A, Mehta C, et al. Multi-proteomic approach to predict specific cardiovascular events in patients with diabetes and myocardial infarction: findings from the EXAMINE trial. Clin Res Cardiol 2020. https:// doi.org/10.1007/s00392-020-01729-3.

13. Elharram $M$, Sharma $A$, White $W$, et al. Timing of randomization after an acute coronary syndrome in patients with type 2 diabetes mellitus. Am Heart J. 2020;6:40-51. https://doi.org/10.1016/j.ahj.2020.07.014.

14. Ferreira JP, Lamiral Z, Bakris G, Mehta C, White WB, Zannad F. Red cell distribution width in patients with diabetes and myocardial infarction: an analysis from the EXAMINE trial. Diabetes Obes Metab. 2021;23(7):1580-7. https://doi.org/10.1111/dom.14371.

15. Rossignol P, Masson S, Barlera S, et al. Loss in body weight is an independent prognostic factor for mortality in chronic heart failure: insights from the GISSI-HF and Val-HeFT trials. Eur J Heart Fail. 2015;17(4):424-33. https://doi.org/10.1002/ejhf.240.

16. Pocock SJ, McMurray JJ, Dobson J, et al. Weight loss and mortality risk in patients with chronic heart failure in the candesartan in heart failure: assessment of reduction in mortality and morbidity (CHARM) programme. Eur Heart J. 2008;29(21):2641-50. https://doi.org/10.1093/eurhe artj/ehn420.
17. Kalantar-Zadeh K, Block G, Humphreys MH, Kopple JD. Reverse epidemiology of cardiovascular risk factors in maintenance dialysis patients. Kidney Int. 2003;63(3):793-808. https://doi.org/10.1046/j.1523-1755.2003. 00803.x.

18. Park SJ, Ha KH, Kim DJ. Body mass index and cardiovascular outcomes in patients with acute coronary syndrome by diabetes status: the obesity paradox in a Korean national cohort study. Cardiovasc Diabetol. 2020;10(1):191. https://doi.org/10.1186/s12933-020-01170-w.

19. Pedersen LR, Olsen RH, Anholm C, et al. Effects of 1 year of exercise training versus combined exercise training and weight loss on body composition, low-grade inflammation and lipids in overweight patients with coronary artery disease: a randomized trial. Cardiovasc Diabetol. 2019;1(1):127. https://doi.org/10.1186/s12933-019-0934-X.

20. Chan YH, Chen SW, Chao TF, Kao YW, Huang CY, Chu PH. The impact of weight loss related to risk of new-onset atrial fibrillation in patients with type 2 diabetes mellitus treated with sodium-glucose cotransporter 2 inhibitor. Cardiovasc Diabetol. 2021;30(1):93. https://doi.org/10.1186/ s12933-021-01285-8.

21. Fowkes FG, Rudan D, Rudan I, et al. Comparison of global estimates of prevalence and risk factors for peripheral artery disease in 2000 and 2010 a systematic review and analysis. Lancet. 2013;19(9901):1329-40. https:// doi.org/10.1016/s0140-6736(13)61249-0.

22. Wang A, Green JB, Halperin JL, Piccini JP. Sr. Atrial Fibrillation and Diabetes Mellitus: JACC Review Topic of the Week. J Am Coll Cardiol. 2019;27(8):1107-15. https://doi.org/10.1016/j.jacc.2019.07.020.

23. Jha V, Garcia-Garcia G, Iseki K, et al. Chronic kidney disease: global dimension and perspectives. Lancet. 2013;20(9888):260-72. https://doi.org/10. 1016/s0140-6736(13)60687-x.

24. Mohanram A, Zhang Z, Shahinfar S, Keane WF, Brenner BM, Toto RD. Anemia and end-stage renal disease in patients with type 2 diabetes and nephropathy. Kidney Int. 2004;66(3):1131-8. https://doi.org/10.1111/j. 1523-1755.2004.00863.x.

25. Lala A, McNulty SE, Mentz RJ, et al. Relief and Recurrence of Congestion During and After Hospitalization for Acute Heart Failure: Insights From Diuretic Optimization Strategy Evaluation in Acute Decompensated Heart Failure (DOSE-AHF) and Cardiorenal Rescue Study in Acute Decompensated Heart Failure (CARESS-HF). Circ Heart Fail. 2015;8(4):741-8. https://doi.org/10.1161/circheartfailure.114.001957.

26. Moazzeni SS, Hizomi Arani R, Deravi N, et al. Weight change and risk of cardiovascular disease among adults with type 2 diabetes: more than 14 years of follow-up in the Tehran Lipid and Glucose Study. Cardiovasc Diabetol. 2021;12(1):141. https://doi.org/10.1186/s12933-021-01326-2.

\section{Publisher's Note}

Springer Nature remains neutral with regard to jurisdictional claims in published maps and institutional affiliations.
Ready to submit your research? Choose BMC and benefit from:

- fast, convenient online submission

- thorough peer review by experienced researchers in your field

- rapid publication on acceptance

- support for research data, including large and complex data types

- gold Open Access which fosters wider collaboration and increased citations

- maximum visibility for your research: over $100 \mathrm{M}$ website views per year

At BMC, research is always in progress.

Learn more biomedcentral.com/submissions 